\title{
Study of Antioxidant and Anticorrosion Activity of Some Microwave Synthesized Thiourea Derivative Ligands and Complexes
}

\author{
Ali M Hassan ${ }^{1}$, Zaghloul I Elbialy ${ }^{2}$ and Khalid M Wahdan \\ ${ }^{1}$ Chemistry Department, Faculty of Science, Al -Azhar University, 11884 Cairo, Egypt \\ ${ }^{2}$ Egyptian Organization for Standardization and Quality \\ ${ }^{3}$ Researcher at Chemistry Department, Faculty of Science, Al -Azhar University, 11884 Cairo, Egypt
}

\begin{abstract}
DOI: $10.36348 /$ sijcms.2020.v03i07.001
| Received: 25.08.2020 | Accepted: 02.09.2020 | Published: 15.09.2020

*Corresponding author: Khalid M Wahdan
\end{abstract}

\section{Abstract}

The great need to the antioxidants in our life and the increased demand of thiourea derivatives which exhibit great biological activity as anti-inflammatory, antimicrobial, antitumor, and also act as antioxidants and anticorrosive agents leads us to synthesize: N-(2-chlorophenyl)-N'- benzoyl thiourea $(C B T)$ and $N$-(4-chloro phenyl)- $N$ '- benzoyl thiourea $(P C B T)$ by reflux method and then their metal complexes of $\mathrm{Co}^{\mathrm{II}}, \mathrm{Ni}^{\mathrm{II}}, \mathrm{Cu}^{\mathrm{II}}$ and $\mathrm{Zn}^{\mathrm{II}}$ were synthesized by microwave (green chemistry) in hope to get better activities. The structure of ligands and their complexes have been characterized by using elemental analysis, mass Spectroscopy, FT-IR, UV-Vis., ${ }^{1}$ HNMR and ${ }^{13}$ CNMR. In this study the synthesized compounds were evaluated for their in vitro DPPH radical scavenging activity. They exerted varying degree of scavenging activity toward DPPH radical with $\mathrm{IC}_{50}$ values between 84 and $250 \mu \mathrm{g} / \mathrm{mL}$ which is considered good and acceptable activity when compared with the activity of standard Ascorbic acid which give $\mathrm{IC}_{50}=14.4 \mu \mathrm{g} / \mathrm{mL}$. Also the anticorrosion activity of the two synthesized ligands (CBT) and (PCBT) was evaluated on carbon steel coupons by using weight loss method.

Keywords: Antioxidant activity, DPPH radical scavenging, thiourea derivatives, transition metal complexes, Anticorrosion activity, weight loss method.

Copyright @ 2020: This is an open-access article distributed under the terms of the Creative Commons Attribution license which permits unrestricted use, distribution, and reproduction in any medium for non-commercial use (NonCommercial, or CC-BY-NC) provided the original author and source are credited.

\section{INTRODUCTION}

The reactive oxygen species, which include superoxide anions $\left(\mathrm{O}_{2}^{-}\right)$, hydrogen peroxide $\left(\mathrm{H}_{2} \mathrm{O}_{2}\right)$ and hydroxyl radicals $(\mathrm{OH})$, and Lipid peroxidation, which involves a series of free radical mediated chain reactions processes, are associated with several types of biological damage. Sodium nitroprusside, a vasodilator drug induces oxidative brain injury, which is actually mediated by the hydroxyl radicals generated by iron element in sodium nitroprusside. Our defense system produces glutathione and other thiols which significantly reduce sodium nitroprusside and other reactive oxygen species. But for the neurodegenerative disorders, supplementation with external antioxidant agents is of need. Therefore much attention has been focused on the use of synthetic antioxidants to inhibit lipid peroxidation and to protect from damage due to free radicals[1]. Antioxidants play also an important role as corrosive inhibitor as they have the ability to inhibit oxidation process. There by leading to minimize oxygen which is considered one of the most corrosive agents removed by reductive inhibitors such as amines and hydrazines[2].

$$
\mathrm{O}_{2}+\mathrm{N}_{2} \mathrm{H}_{2} \rightarrow 2 \mathrm{H}_{2} \mathrm{O}+\mathrm{N}_{2} \text { In this example, }
$$
hydrazine converts oxygen, a common corrosive agent, to water, which is generally benign. The problem of corrosion is common and occurs in various sectors, such as chemical industry, petrochemical, shipbuilding, construction, automotive, aviation, railway, maritime and others. The consequences of corrosion can result in economic loss, for example, the oxidation of residential pipes, vehicles and metal materials in general, but can also result in serious accidents, causing damage to both nature and man, for example, degradation in pipeline systems, bridge failures, and others[3, 4]. Coordination compounds possess high attention due to their structural variety, interesting physical \& chemical properties and promising applications in many fields. Metal ions play an important role in the structure and function of many bio macromolecules and have important roles in the biological processes of metabolism as well as in pharmaceutical chemistry due to their chemical 
properties. Compounds bearing carbonyl and thiocarbonyl groups are used as potential donor ligand for the preparation of complexes[5, 6]. Among these, thiourea and its derivatives are versatile ligands that coordinate to form stable compounds. They are able to coordinate with metal either as neutral or monoanion or dianion ligand[7]. These thiourea ligands and their metal complexes were reported to act as antioxidants, antimicrobial, antibacterial, antifungal, antimalarial, anti-tuberculosis, anticancer activities and anticorrosive agents. In view of the importance of thiourea and their derivatives it was important to synthesize $\mathrm{N}$-substituted thiourea ligand and their complexes with transition metal elements because it was observed that this activity was enhanced by complexing with certain transition metal elements[7]. Complexes were synthesized using microwave-assisted irradiation. Microwave gives shorter reaction times, clean, high yields and low cost[7, 8]. A rapid, simple and inexpensive method to measure antioxidant activity is the use of the free radical, 2, 2-Diphenyl-1picrylhydrazyl (DPPH) which is widely used to test the ability of compounds to act as free radical scavengers or hydrogen donors and to evaluate antioxidant activity[9]. The DPPH assay method is based on the reduction of DPPH, a stable free radical[10]. The free radical DPPH with an odd electron gives a maximum absorption at $517 \mathrm{~nm}$ (purple color). When Antioxidants react with $\mathrm{DPPH}$, which is a stable free radical becomes paired off in the presence of a hydrogen donor (e.g., a free radical scavenging antioxidant) and is reduced to the DPPHH and as consequence the absorbance's decreased from the DPPH[11] Radical to the DPPH-H form, results in decolorization (yellow color) with respect to the number of electrons captured[12]. More the decolorization more is the reducing ability. This test has been the most accepted model for evaluating the free radical scavenging activity of any new drug[13]. When a solution of DPPH is mixed with that of a substance that can donate a hydrogen atom, it rises to the reduced form (Diphenylpicrylhydrazine; non radical) with the loss of this violet color (although there would be expected to be a residual pale yellow color from the picryl group still present)[14].

\section{EXPERIMENTAL}

\section{Synthesis of ligands:}

The two Ligands were prepared by reflux method between $0.1 \mathrm{~m}$ of ammonium thiocyanate in acetone and $0.1 \mathrm{~m}$ of benzoyl chloride to form Benzoyl thiocyanate. Then Benzoyl thiocyanate refluxed with ortho chloro analin and para chloro analin to form: $\mathrm{N}$ (2-chlorophenyl)- $N$ '- benzoyl thiourea $(C B T)$ and $N$-(4chloro phenyl)-N'- benzoyl thiourea (PCBT) respectively[19, 20].

\section{Synthesis of Metal Complexes}

The prepared ligand and the acetate salts of the metals: $\mathrm{Co}\left(\mathrm{CH}_{3} \mathrm{COO}\right)_{2} \cdot 4 \mathrm{H}_{2} \mathrm{O}, \mathrm{Ni}\left(\mathrm{CH}_{3} \mathrm{COO}\right)_{2} \cdot 4 \mathrm{H}_{2} \mathrm{O}$, $\mathrm{Cu}\left(\mathrm{CH}_{3} \mathrm{COO}\right)_{2} \cdot \mathrm{H}_{2} \mathrm{O}$ and $\mathrm{Zn}\left(\mathrm{CH}_{3} \mathrm{COO}\right)_{2} \cdot 2 \mathrm{H}_{2} \mathrm{O}$ were mixed in (1:1) ratio. Then irradiated in microwave for (3-5 $\mathrm{min}$ ) to give the complexes with higher yields [19, 20]. Synthesis of N-(2-chlorophenyl)-N'-Benzoyl thiourea (CBT), N-(4-chloro phenyl)-N'- benzoyl thiourea (PCBT) and their metal complexes given in scheme 1 and 2.

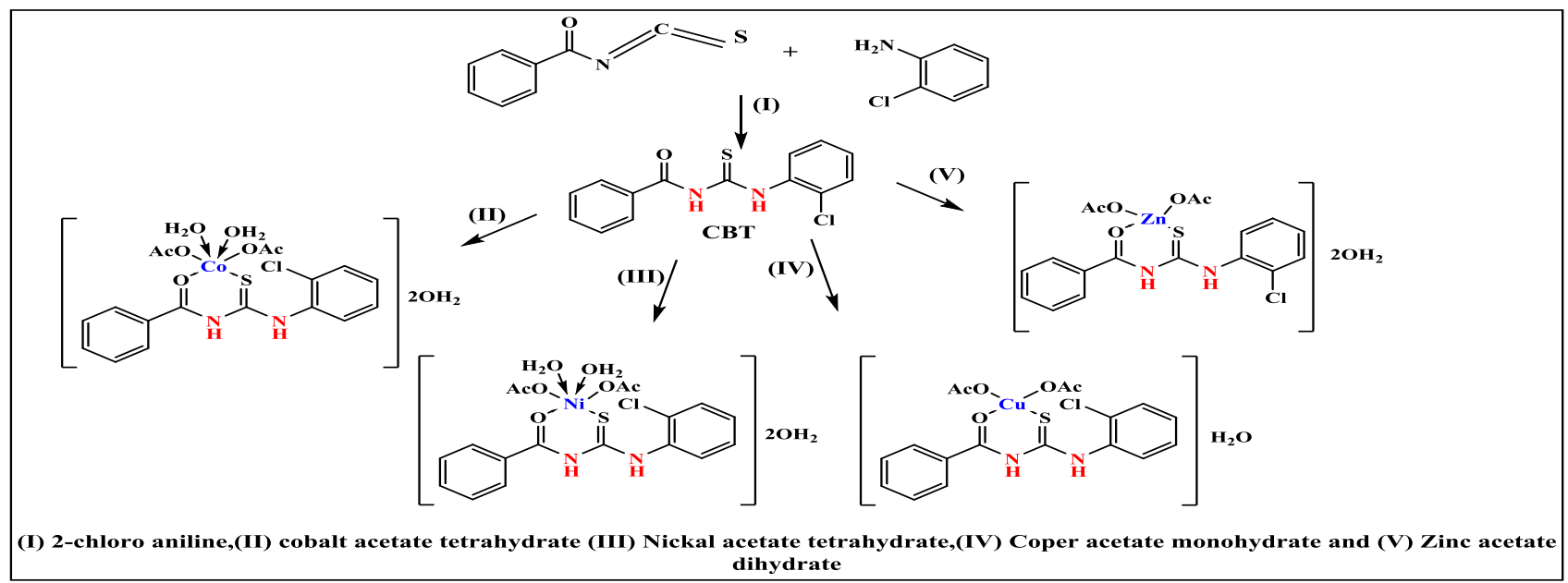

Scheme-1: Synthesis of N-(2-chlorophenyl)-N'-Benzoyl thiourea (CBT) and its metal Complexes 


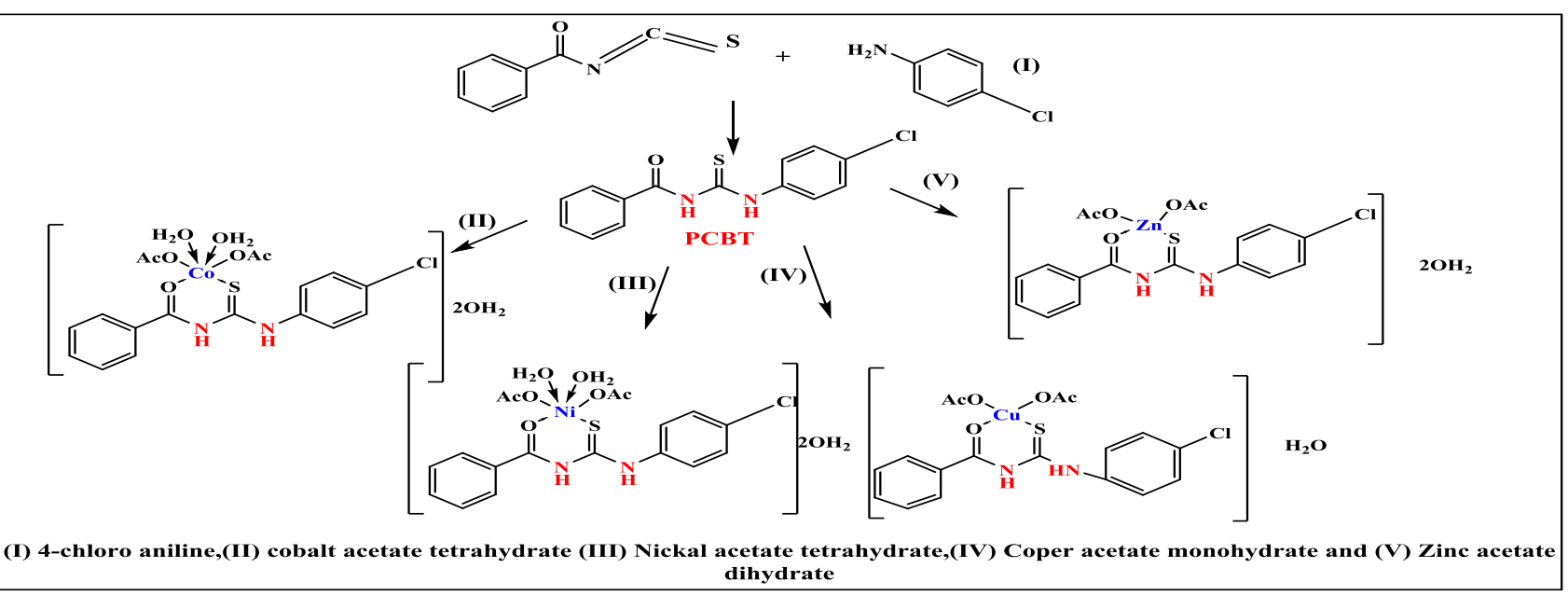

Scheme-2: Synthesis of N-(p-chlorophenyl)-N'-Benzoyl thiourea (PCBT) and its metal Complexes

\section{Evaluation of antioxidant activity by DPPH radical scavenging method:}

Freshly prepared $(0.004 \% \mathrm{w} / \mathrm{v})$ methanol solution of 2, 2-diphenyl-1-picrylhydrazyl (DPPH) radical was prepared and stored at $10{ }^{\circ} \mathrm{C}$ in the dark. A DMSO solution of the test compound was prepared by dilution method[15]. The mixtures were then allowed to react in the dark for half an hour. Measurement of the mixture absorbance was achieved spectrophotometrically at $515 \mathrm{~nm}$. Absorbance measurements were recorded immediately with a UVvisible spectrophotometer (UV-3101PC)[16]. The absorbance of the DPPH radical without antioxidant (control) and the reference compound ascorbic acid were also measured. All the determinations were performed in three replicates[17] and averaged. The percentage of the DPPH radical scavenging activity was calculated according to the equation: $\mathrm{PI}=[(\mathrm{AC}-\mathrm{AS}) /$ AC) $x$ 100].

Where: AC $=$ Absorbance of the control [18] and AS = absorbance of the (sample $+\mathrm{DPPH})$.

\section{Corrosion Inhibition studies:}

Corrosion inhibition behavior of the two synthesized ligands (CBT) and (PCBT) was evaluated on carbon steel coupons by using weight loss measurements as follows:

The surface of the carbon steel coupons was abraded successively by different grade of metallographic emery papers until the surface appears free from any scratches and other apparent defects, then degreased with hot acetone, washed with distilled water and finally dried at room temperature. Tests were conducted on carbon steel coupons of the following composition: $(0.11 \% \mathrm{C}$, $0.45 \% \mathrm{Mn}, 0.04 \% \mathrm{P}, 0.05 \% \mathrm{~S}, 0.25 \% \mathrm{Si}$, and the remained is $\mathrm{Fe}$ ). The concentrations of the prepared ligands were $0.5 \times 10-4 \mathrm{M}, 0.75 \times 10-4 \mathrm{M}, 2.5 \times 10-4$ $\mathrm{M}, 5 \times 10-4 \mathrm{M}$, and $7.5 \times 10^{-4} \mathrm{M}$. All solutions were prepared using distilled water. The experiments were carried out using carbon steel coupons immersed in 1.0 $\mathrm{M} \mathrm{HCl}$ solution in absence and presence of different concentrations of the two synthesized ligands. Tests were conducted under total immersion conditions in $100 \mathrm{ml}$ of the aerated test solutions. To determine weight loss with respect to time, test coupons were retrieved after $24 \mathrm{~h}$ immersion time, scrubbed with a bristle brush, washed, dried, and reweighed. The weight loss was taken as the difference between the initial and final weights of the coupons. Weight loss measurements were done at $30^{\circ} \mathrm{C}$.

\section{RESULTS AND DISCUSSION \\ Mass spectroscopy:}

The mass spectra of CBT (Fig.1) (Scheme 3) show multi peak representing successive degradation of the ligand. The spectra show the peak $\mathrm{m} / \mathrm{e}=292.74$ represent the molecular ion peak $\left(\mathrm{C}_{14} \mathrm{H}_{11} \mathrm{ON}_{2} \mathrm{SCl}\right)$ with $39.57 \%$ abundance. The base peak $100 \%$ with $\mathrm{m} / \mathrm{e}$ $=145.79$. 


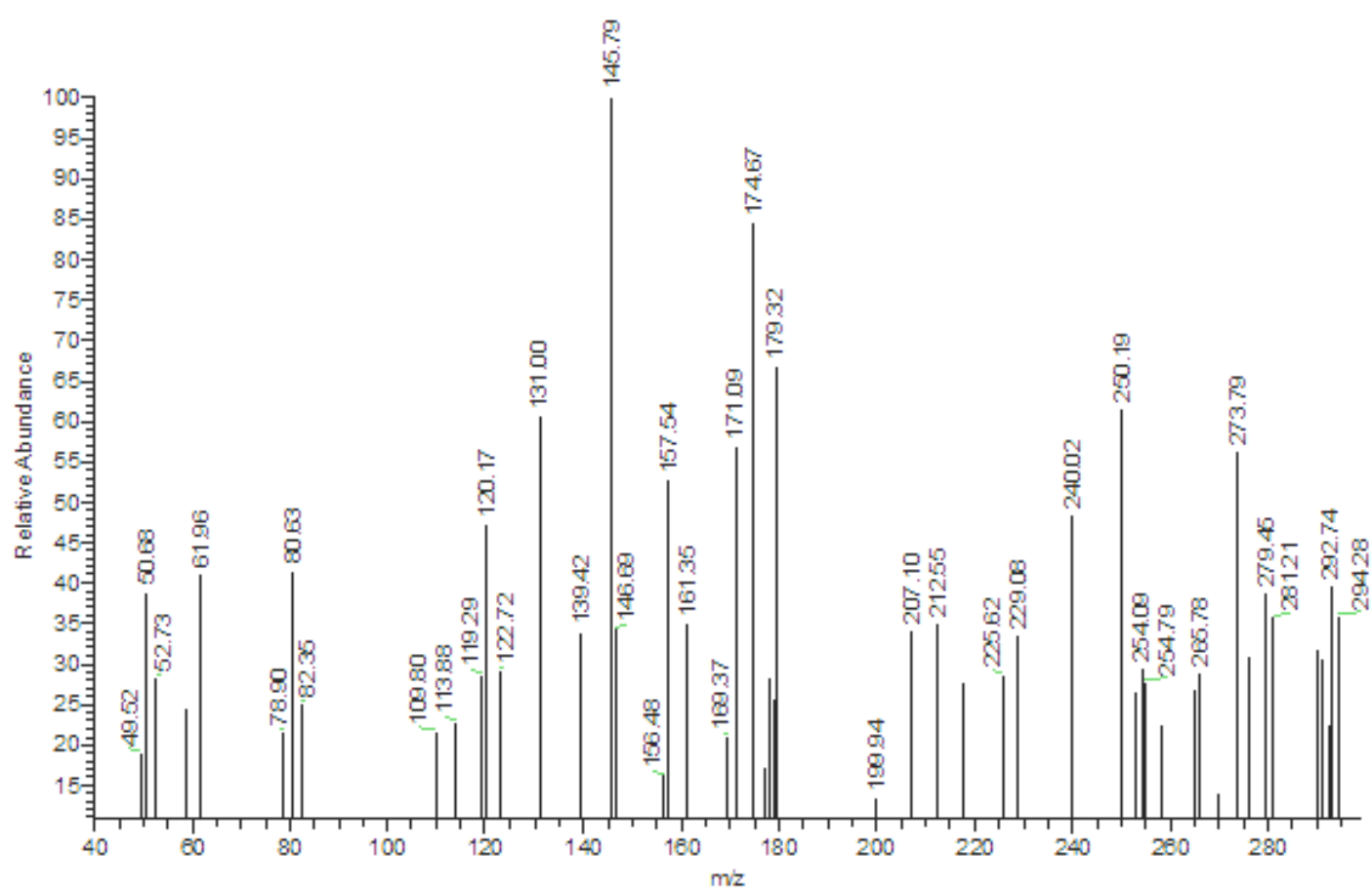

Figure-1: Mass spectra of the prepared ligand (CBT)

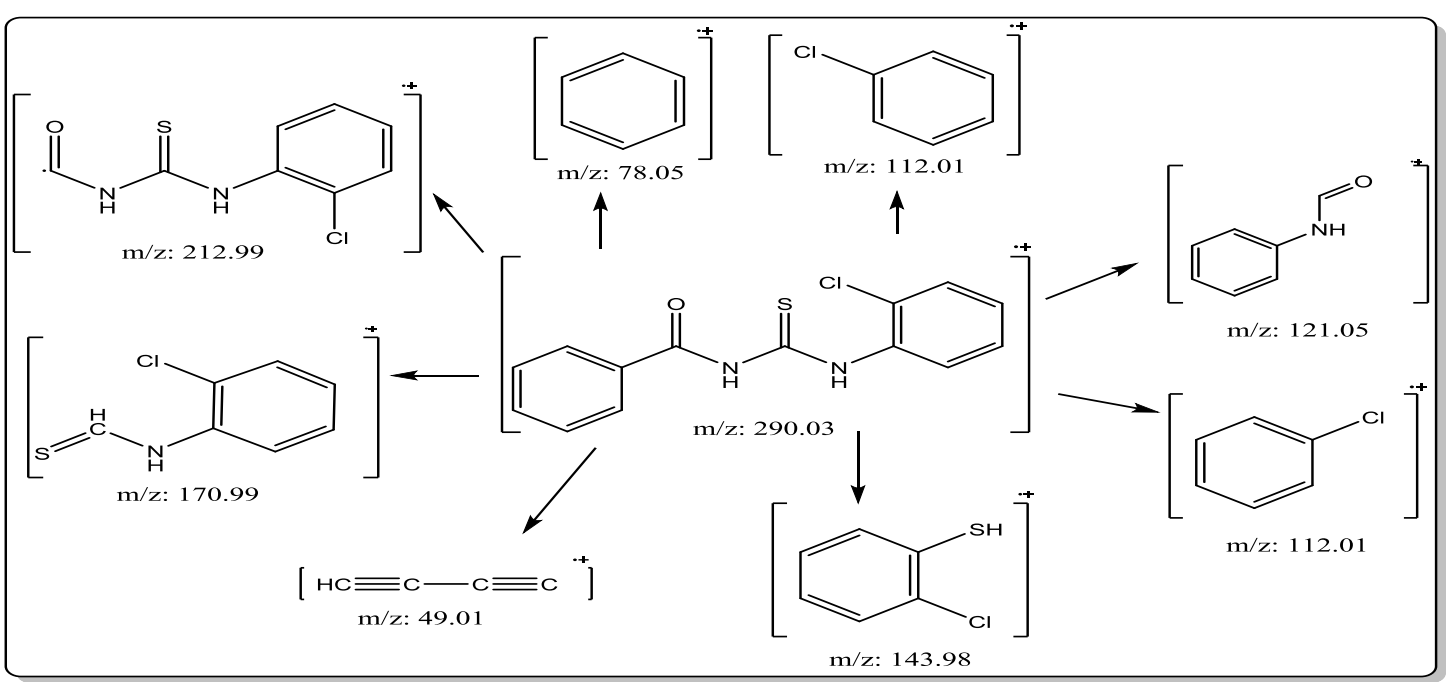

Scheme3: Suggested mass fragmentation patterns of the prepared ligand (CBT)

The mass spectra of PCBT (Fig.2) (Scheme 4) show multi peak representing successive degradation of the ligand. The spectra show the peak $\mathrm{m} / \mathrm{e}=290.77$ represent the molecular ion peak $\left(\mathrm{C}_{14} \mathrm{H}_{11} \mathrm{ON}_{2} \mathrm{SCl}\right)$ with $52.7 \%$ abundance. The base peak $100 \%$ with $\mathrm{m} / \mathrm{e}$ $=106.06$. 


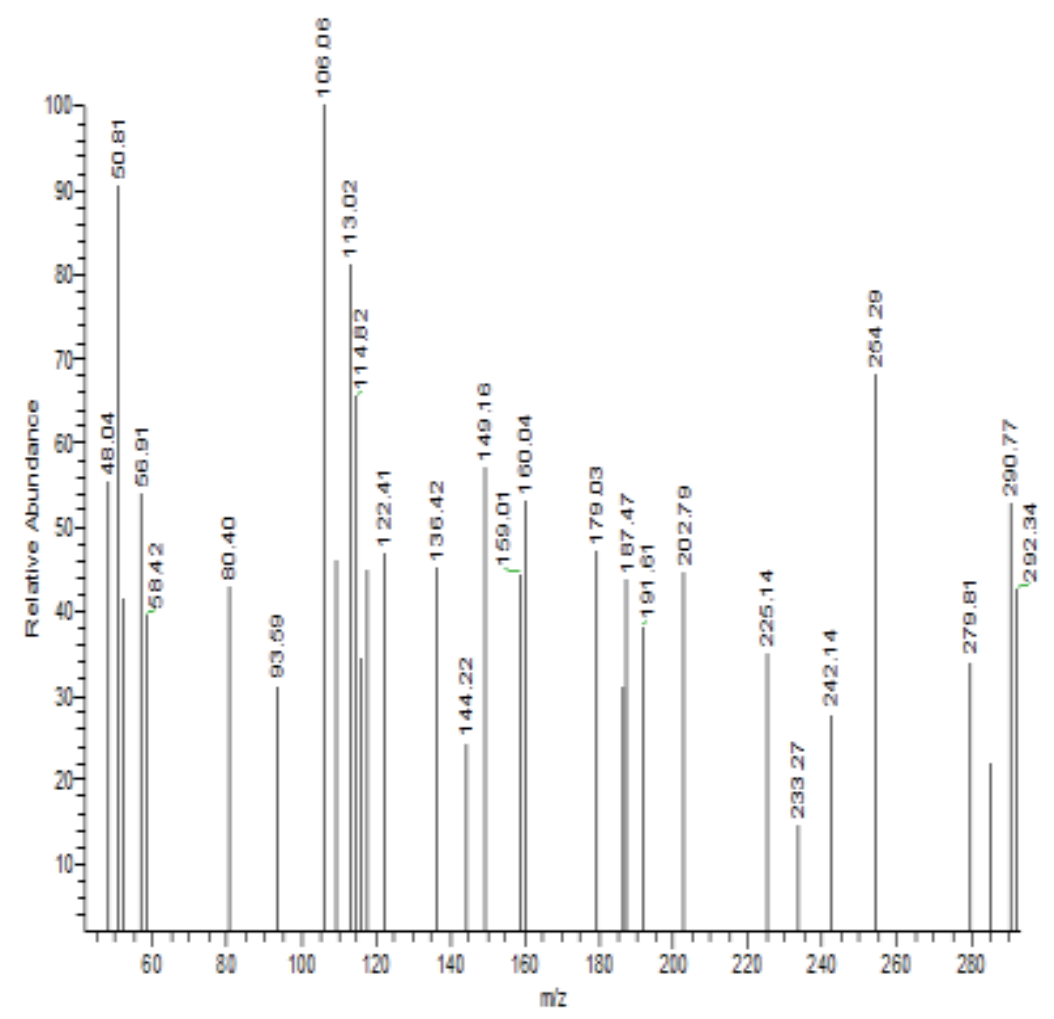

Figure-2: Mass spectra of the prepared ligand (PCBT)

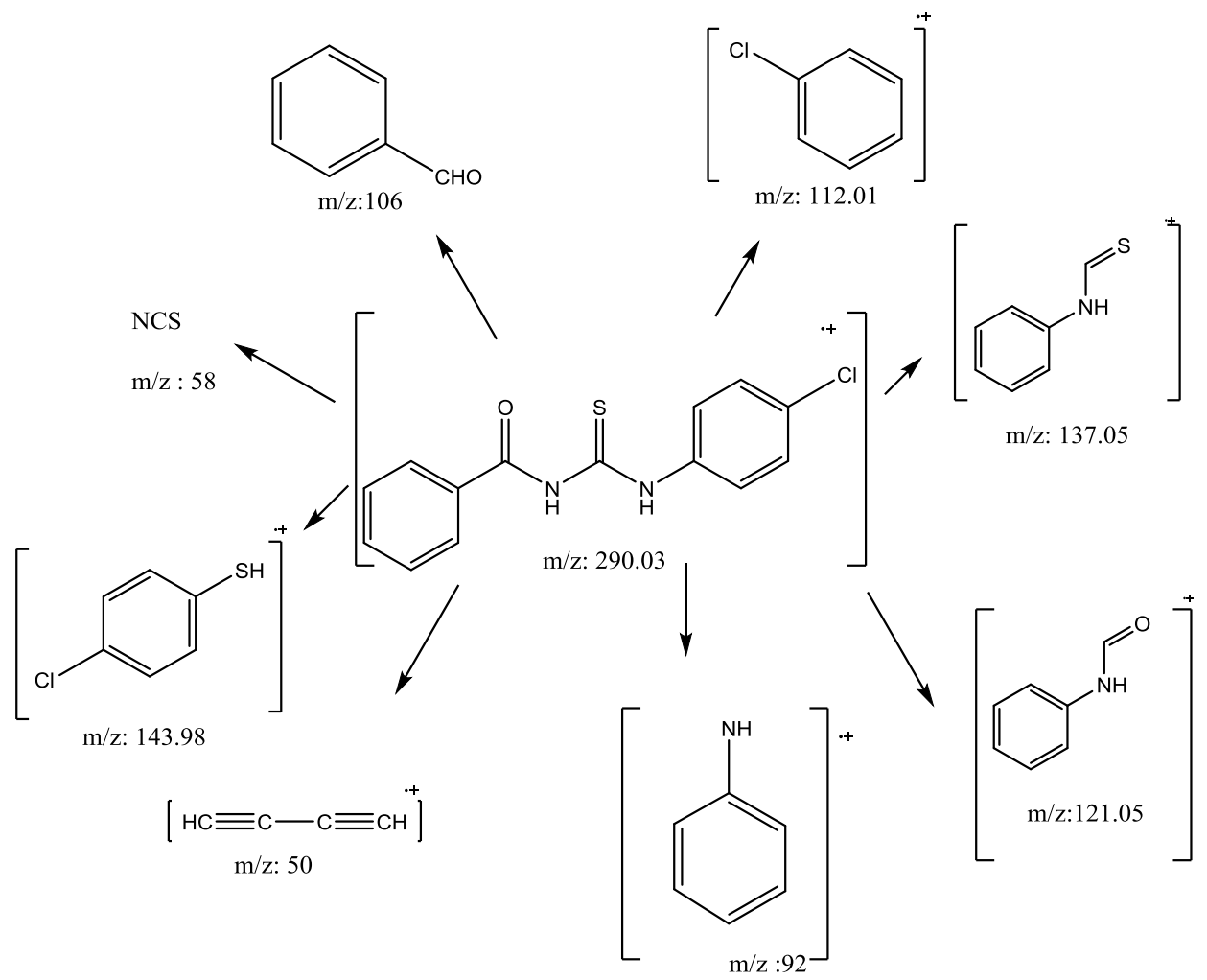

Scheme4: Suggested mass fragmentation patterns of the prepared ligand (PCBT)

The mass spectra of Zn-CBT (Fig.3) (Scheme: 5) show multi peak representing successive degradation of the ligand. The spectra show the peak $\mathrm{m} / \mathrm{e}=510.94$ represent the molecular ion peak $\left(\mathrm{C}_{18} \mathrm{H}_{21} \mathrm{O} 7 \mathrm{~N}_{2} \mathrm{SCl}\right)$ with $21.06 \%$ abundance. The base peak $100 \%$ with $\mathrm{m} / \mathrm{e}$ $=52.62$. 


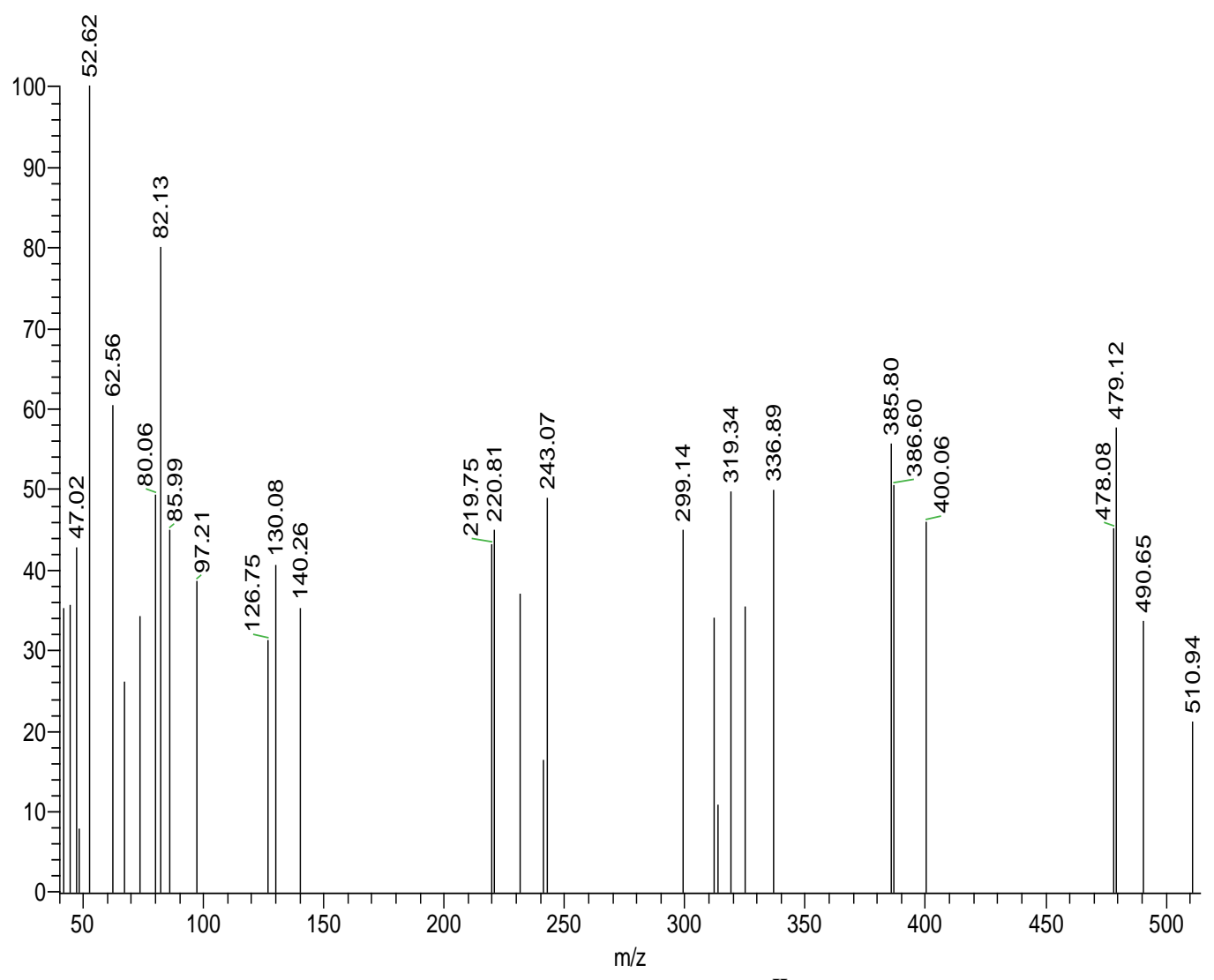

Figure-3: Mass spectra of the prepared $\mathrm{Zn}^{\mathrm{II}}$ complex of CBT

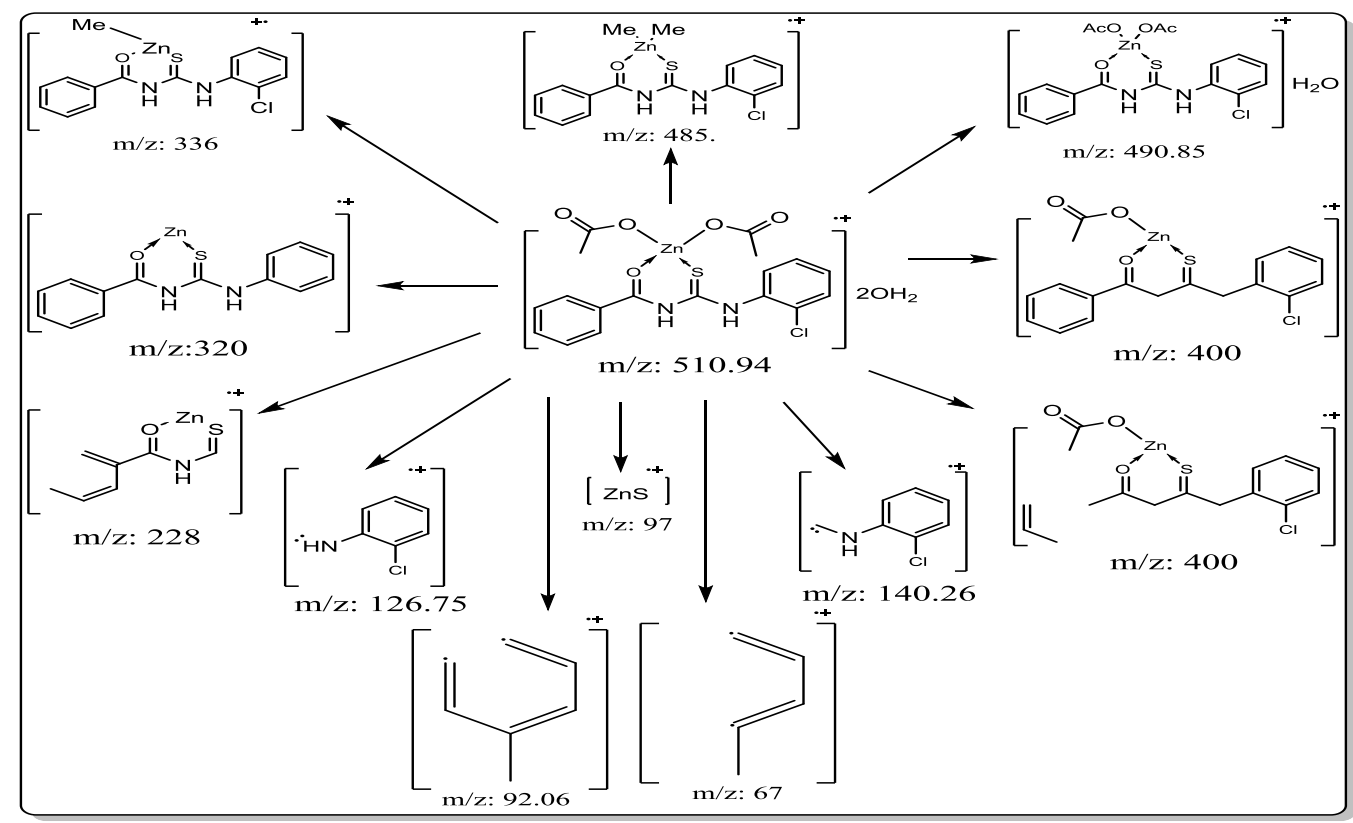

Scheme 5: Suggested mass fragmentation patterns of the prepared Zn complex of CBT

The mass spectra of Co-PCBT (Fig.4) (Scheme: 6) show multi peak representing successive degradation of the ligand. The spectra show the peak $\mathrm{m} / \mathrm{e}=539.33$ represent the molecular ion peak $\left(\mathrm{C}_{18} \mathrm{H}_{25} \mathrm{O} 9 \mathrm{~N}_{2} \mathrm{SCl}\right)$ with $22.52 \%$ abundance. The base peak $100 \%$ with $\mathrm{m} / \mathrm{e}=316.6$. 


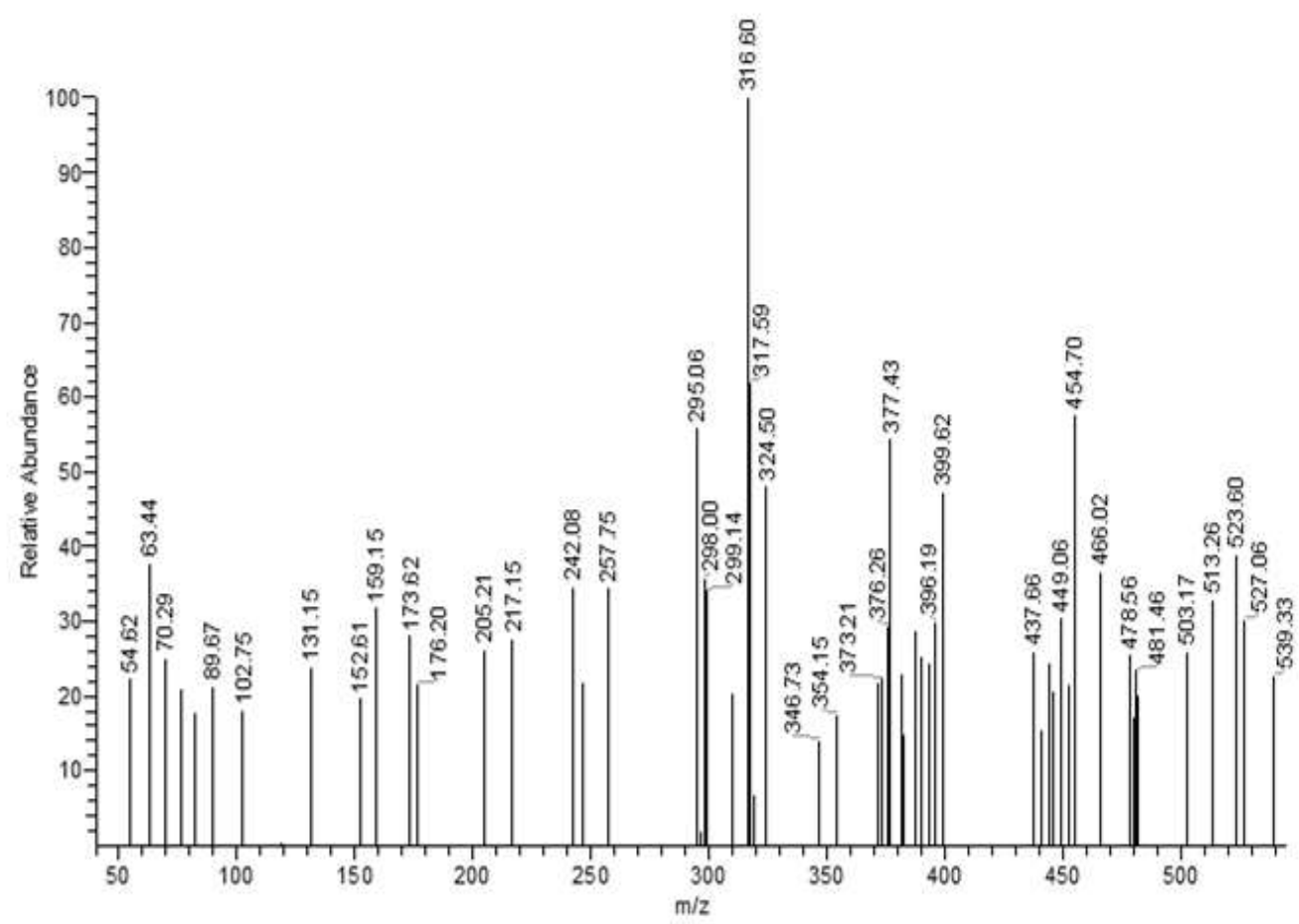

Figure-4: Mass spectra of the prepared Co ${ }^{\mathrm{II}}$ complex of PCBT

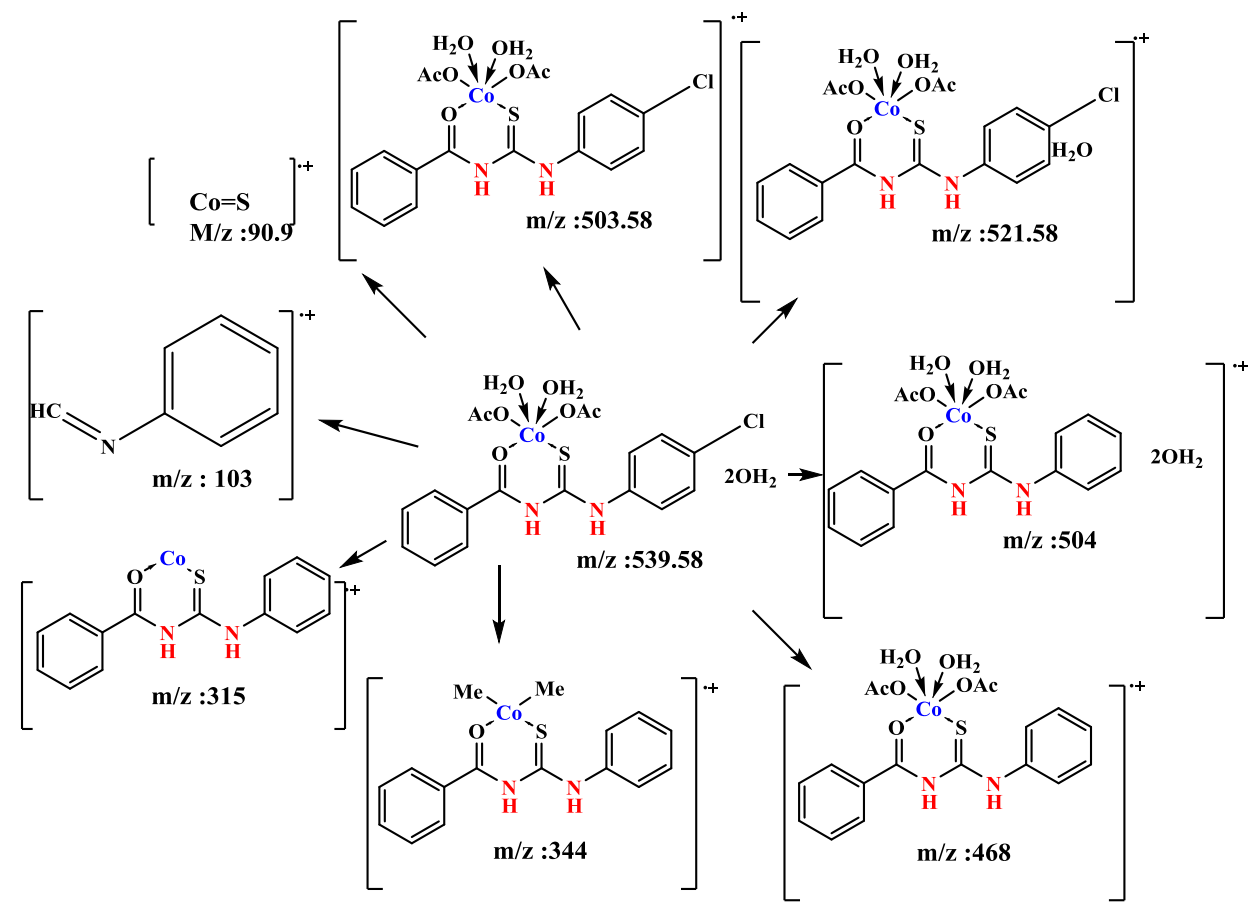

Scheme 6: Suggested mass fragmentation patterns of the prepared Co (II) complex of PCBT

\section{$H^{1}$ NMR Spectroscopy:}

For the ligand (CBT) fig.5 give two singlet signals, one at $\delta 11.78 \mathrm{ppm}$ assigned to $(\mathrm{S}, 1 \mathrm{H}, \mathrm{N} 8-\mathrm{H})$ and the other at $\delta 12.742 \mathrm{ppm}$ assigned to $(\mathrm{S}, 1 \mathrm{H}, \mathrm{N} 10-$
H) [22] (which were also identified by $\mathrm{D}_{2} \mathrm{O}$ exchange) . The multiplets observed at $\delta 7.293-8.098 \mathrm{ppm}$ are attributed to the phenyl protons. 


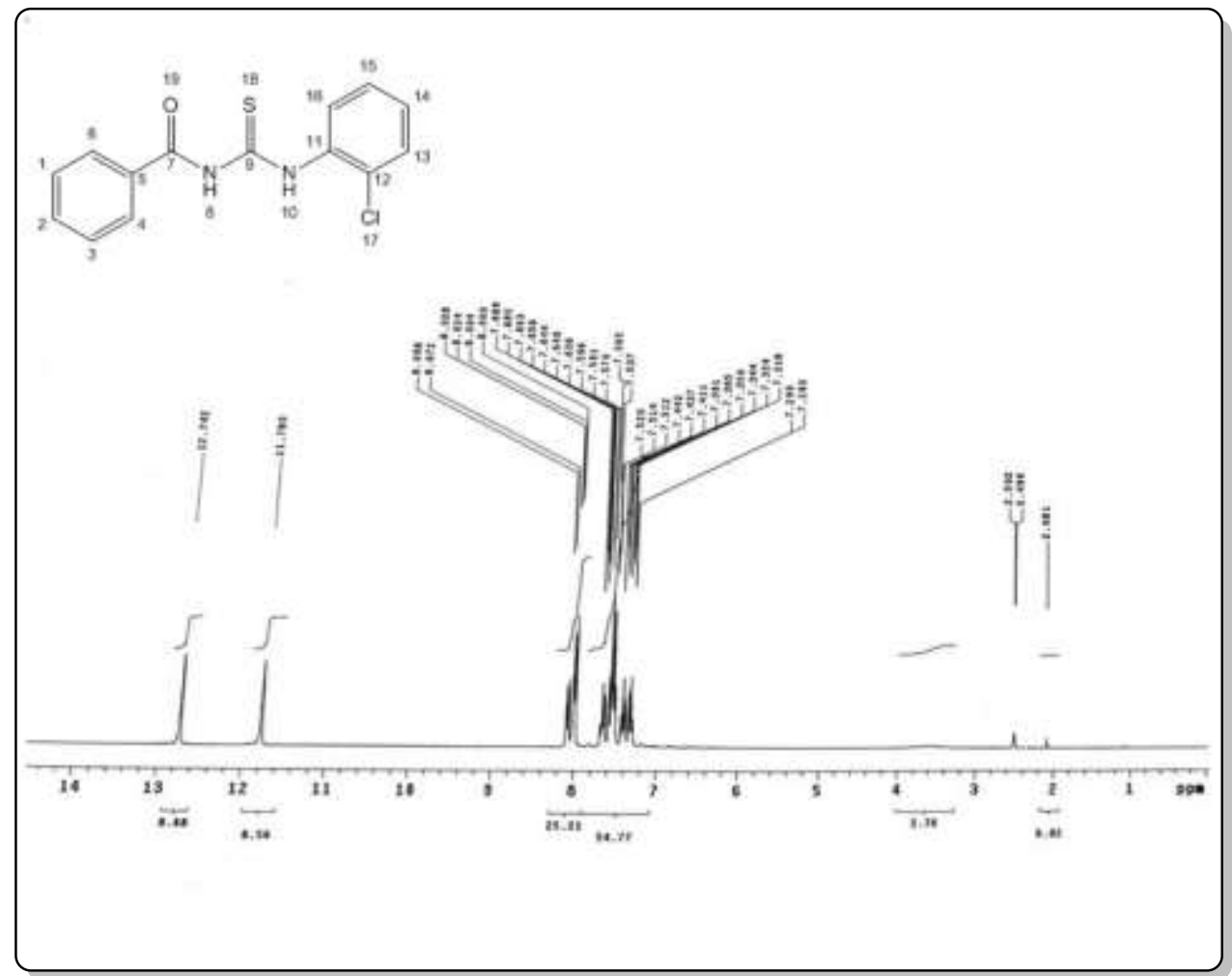

Figure-5: 1H NMR spectra of the ligand (CBT)

For ligand (PCBT) fig. 6 give two singlet signals, one at $\delta 11.58 \mathrm{ppm}$ assigned to $(\mathrm{S}, 1 \mathrm{H}, \mathrm{N} 8-\mathrm{H})$ and the other at $\delta 12.59 \mathrm{ppm}$ assigned to $(\mathrm{S}, 1 \mathrm{H}, \mathrm{N} 10-\mathrm{H})$
[22] (which were also identified by $\mathrm{D}_{2} \mathrm{O}$ exchange) . The multiplets observed at $\delta 7.450-8.000 \mathrm{ppm}$ are attributed to the phenyl protons.

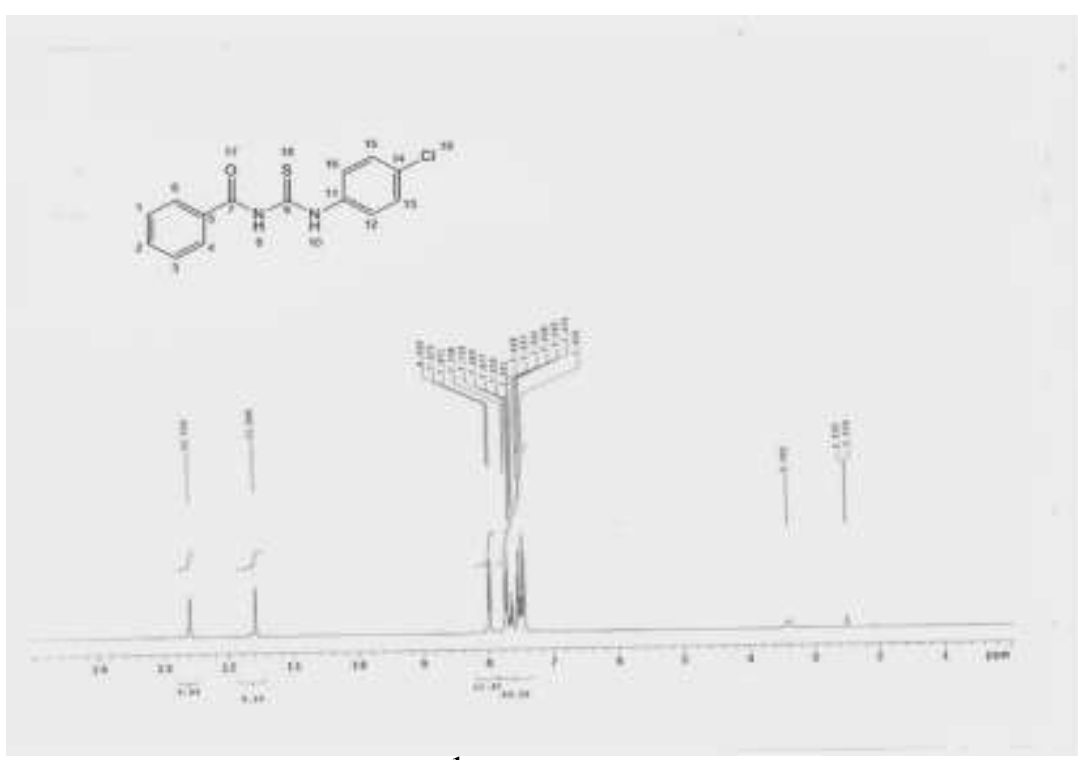

Figure-6: $\mathrm{H}^{1} \mathrm{NMR}$ Spectra of PCBT

\section{${ }^{13}$ CNMR spectroscopy:}

The ${ }^{13}$ CNMR spectra of the synthesized ligand (CBT) fig.7 showed peaks at $180.219 \mathrm{ppm}$ assigned to $(\mathrm{C}=\mathrm{O}), 168.556 \mathrm{ppm}$ assigned to $(\mathrm{C}=\mathrm{s}), 135.357 \mathrm{ppm}$
(C11) $133.239 \quad \operatorname{ppm}(\mathrm{C} 16), 131.858 \quad \mathrm{ppm}, \quad$ (C5) ,129.483ppm(C2) and at $128.793 \mathrm{ppm}(\mathrm{C} 12), 128.261$ ppm(C13), $128.110 \mathrm{ppm}(\mathrm{C} 1$ and C3), $126.167 \mathrm{ppm}(\mathrm{C} 4$ and $\mathrm{C} 6$ ). 


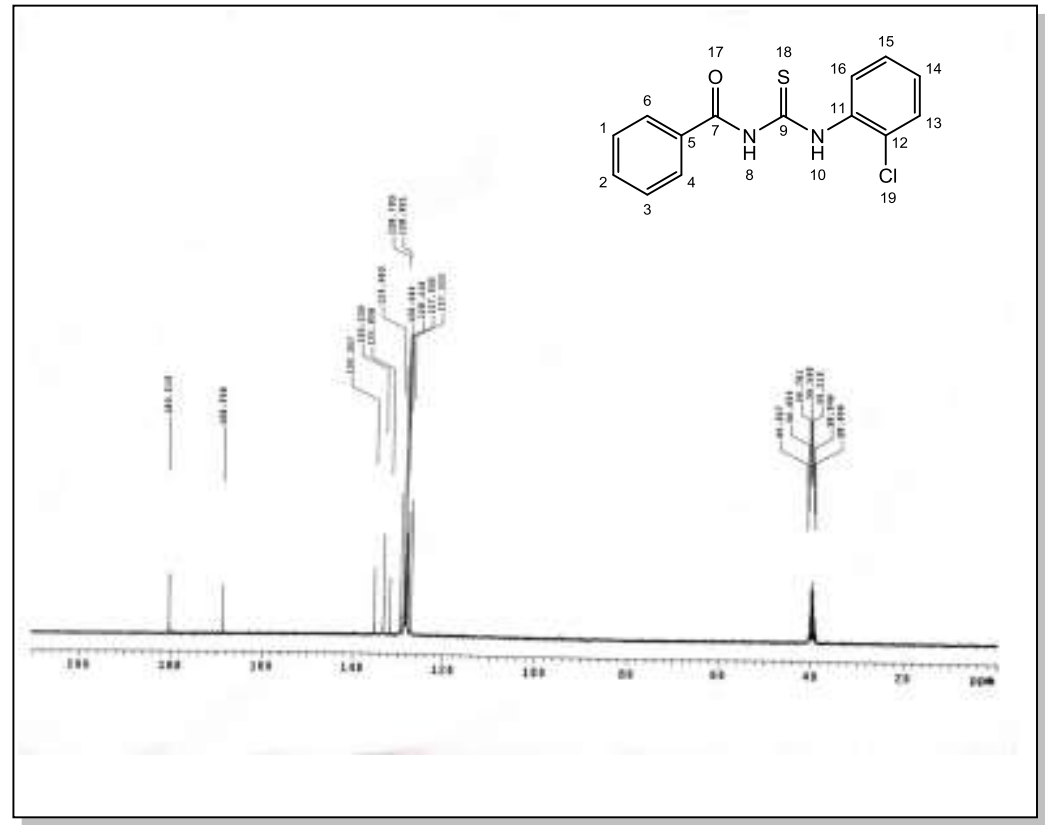

Figure-7: 13C NMR spectra of the ligand (CBT)

The ${ }^{13}$ CNMR spectra of the synthesized ligand (PCBT) fig.8 showed peaks at $179.347 \mathrm{ppm}$ assigned to $(\mathrm{C}=\mathrm{O}), 168.207 \mathrm{ppm}$ assigned to $(\mathrm{C}=\mathrm{S})$, $136.958 \mathrm{ppm}$ to (C11) $133.133 \mathrm{ppm}$ to $(\mathrm{C} 14), 132.63$ ppm to (C5), $130.257 \mathrm{ppm}$ to (C2) ,130.257 ppm to
$(\mathrm{C} 12, \mathrm{C} 16)$ and at $128.694 \mathrm{ppm}(\mathrm{C} 13, \mathrm{C} 15), 128.550$ ppm (C1,C3), $126.167 \mathrm{ppm}(\mathrm{C} 4$ and $\mathrm{C} 6)$.

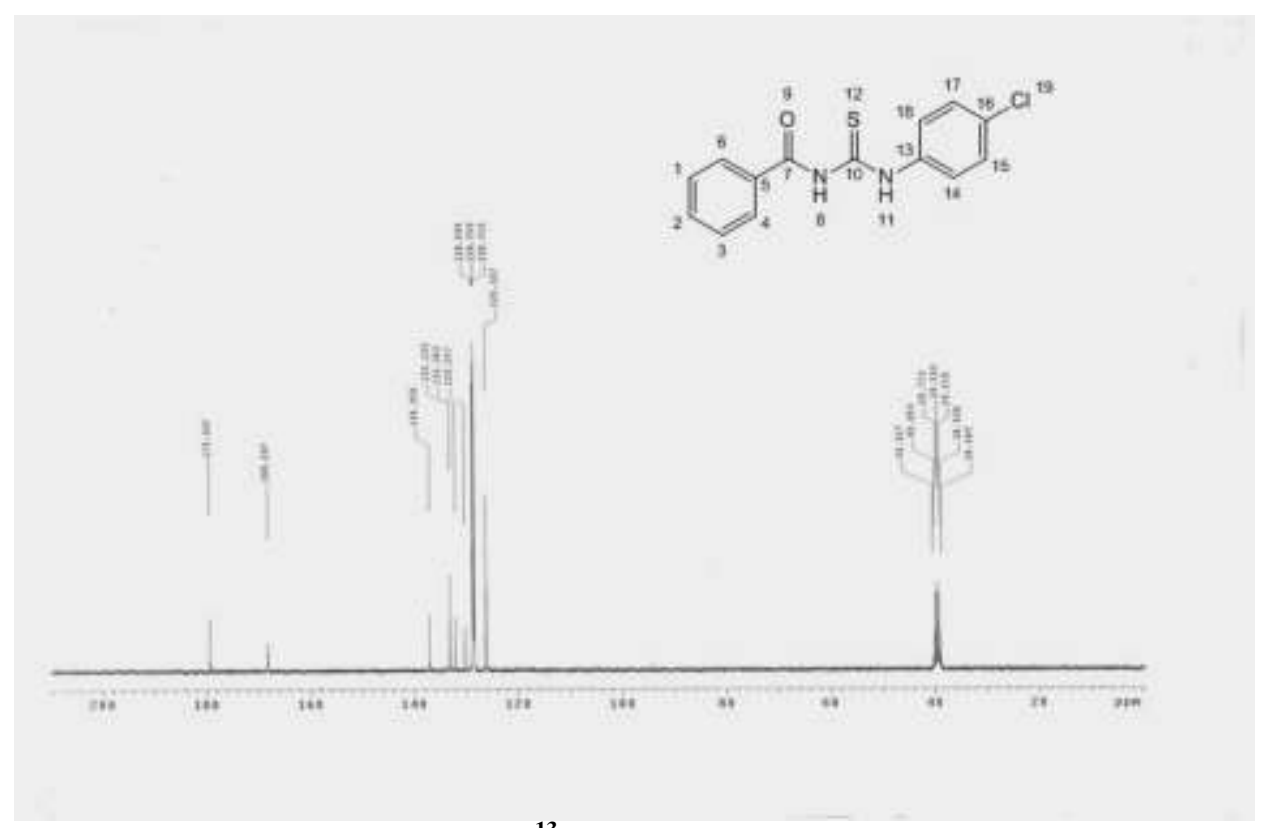

Figure-8: $\mathrm{C}^{13}$ NMR Spectra of PCBT

\section{IR spectra:}

The characteristic IR bands of the thiourea ligands showed the expected frequencies of $v(\mathrm{C}=\mathrm{O}), v$ $(\mathrm{N}-\mathrm{H}), v(\mathrm{C}-\mathrm{N})$ and $v(\mathrm{C}=\mathrm{S})$ and upon coordination of the metal center to ligand, these characteristic bands were found to be shifted to a lower frequency. This finding may be taken as an evidence for the coordination of the carbonyl oxygen and thionyl Sulphur atoms with the metal. The IR data of ligands and complexes are tabulated in Table1 and $2[19,20]$. 
Table 1:I.R bands of the synthesized ligand CBT and its complexes

\begin{tabular}{|c|c|c|c|c|c|c|c|c|c|}
\hline Cpd. & $\begin{array}{c}\text { v OH } \\
(\mathrm{H} 2 \mathrm{O})\end{array}$ & v N-H & $\begin{array}{c}\text { v C-H } \\
\text { Aromatic }\end{array}$ & $\begin{array}{c}\text { v OAc } \\
\text { Assym. } \\
\text { /Sym. } \\
\end{array}$ & v $\mathbf{C}=\mathbf{O}$ & v $\mathbf{C}=\mathbf{S}$ & vPh-Cl & v M-O & v M-S \\
\hline CBT & -- & 3312 & 3018 & -- & 1669 & 1329 & 753 & -- & -- \\
\hline $\begin{array}{c}\text { CBT- } \\
\text { Co }\end{array}$ & 3850 & 3310 & 3016 & 1435 & 1666 & 1249 & 679 & 594 & 540 \\
\hline CBT-Ni & 3700 & 3309 & 3016 & 1427 & 1666 & 1242 & 678 & 594 & 509 \\
\hline $\begin{array}{c}\text { CBT- } \\
\mathrm{Cu}\end{array}$ & 3850 & 3371 & 3016 & 1442 & 1597 & 1242 & 694 & 578 & 532 \\
\hline $\begin{array}{c}\text { CBT- } \\
\text { Zn }\end{array}$ & 3448 & 3209 & 3008 & 1404 & 1601 & 1288 & 686 & 617 & 501 \\
\hline Cpd. & $\begin{array}{c}\text { v OH } \\
(\mathbf{H} 20)\end{array}$ & v N-H & $\begin{array}{c}\text { v C-H } \\
\text { Aromatic }\end{array}$ & $\begin{array}{c}\text { v OAc } \\
\text { Assym. } \\
\text { /Sym. }\end{array}$ & v $\mathbf{C}=\mathbf{O}$ & v $\mathbf{C}=\mathbf{S}$ & vPh-Cl & v M-O & v M-S \\
\hline PCBT & -- & 3251 & 3020 & -- & 1670 & 1341 & 765 & -- & -- \\
\hline $\begin{array}{c}\text { PCBT- } \\
\text { Co }\end{array}$ & 3742 & 3348 & 3148 & 1396 & 1550 & 1273 & 679 & 609 & 501 \\
\hline $\begin{array}{c}\text { PCBT- } \\
\mathrm{Ni}\end{array}$ & 3850 & 3441 & 2993 & 1412 & 1535 & 1250 & 686 & 609 & 509 \\
\hline $\begin{array}{c}\text { PCBT- } \\
\mathrm{Cu}\end{array}$ & 3700 & 3487 & 3148 & 1442 & 1605 & 1273 & 694 & 625 & 501 \\
\hline $\begin{array}{c}\text { PCBT- } \\
\text { Zn }\end{array}$ & 3850 & 3464 & 3009 & 1342 & 1535 & 1250 & 686 & 609 & 501 \\
\hline
\end{tabular}

Electronic and magnetic properties of the prepared compounds

The stereochemistry of the metal ions in the complexes can be assigned via the electronic spectral measurements. The spectra of the ligands and there complexes in solid-state showed a number of bands in the UV -Vis region (200-800 nm) table 3, 4 [19, 20].

Table-3: Electronic Spectra, magnetic for CBT metal complex

\begin{tabular}{|c|c|c|c|c|}
\hline Cpd & $\begin{array}{c}\lambda_{\max }, \\
\mathbf{n m}\end{array}$ & Assignments & $\boldsymbol{\mu}_{\text {eff. }}(\mathbf{B} . \mathrm{M})$ & $\begin{array}{c}\text { Suggested } \\
\text { Structure }\end{array}$ \\
\hline CBT & 330 & $\begin{array}{c}\left(\mathrm{n}-\pi^{*}, \mathrm{C}=\mathrm{O}\right), \\
\left(\mathrm{n}-\pi^{*}, \mathrm{C}=\mathrm{N}\right), \\
\left(\pi-\pi^{*}, \text { aromatic }\right. \\
\text { ring })\end{array}$ & -- & - \\
\hline CBT-Co & $425-650$ & $\begin{array}{c}4 \mathrm{~T} 1 \mathrm{~g}(\mathrm{~F}) \\
\rightarrow 4 \mathrm{~T} 1 \mathrm{~g}(\mathrm{P}) 4 \mathrm{~T} 1 \mathrm{~g} \\
(\mathrm{~F}) \rightarrow 4 \mathrm{~T} 2 \mathrm{~g}\end{array}$ & 5.8 & Octahedral \\
& 260 & ${ }^{3} \mathrm{~A}_{2} \mathrm{~g} \rightarrow{ }^{3} \mathrm{~T}_{1} \mathrm{~g}(\mathrm{P})$ & 2.9 & Octahedral \\
\hline CBT-Ni & $450-$ & $\mathrm{A}_{2} \mathrm{~g} \rightarrow{ }^{3} \mathrm{~T}_{2} \mathrm{~g}$ & & Tetrahedral \\
\hline CBT-Cu & $425-750$ & $2 \mathrm{~B} 2 \rightarrow 2 \mathrm{E}$ & 1.78 & Tetrahedral \\
\hline CBT-Zn & $560-$ & $\mathrm{MLCT}$ & $\mathrm{Di}$ & \\
\hline
\end{tabular}


Table-4: Electronic Spectra, magnetic for PCBT metal complex

\begin{tabular}{|c|c|c|c|c|}
\hline Cpd & $\begin{array}{c}\lambda_{\text {max }}, \\
\mathbf{n m}\end{array}$ & Assignments & $\boldsymbol{\mu}_{\text {eff. }}(\mathbf{B . M})$ & $\begin{array}{c}\text { Suggested } \\
\text { Structure }\end{array}$ \\
\hline pCBT & 325 & $\begin{array}{c}\left(\mathrm{n}-\pi^{*}, \mathrm{C}=\mathrm{O}\right), \\
\left(\mathrm{n}-\pi^{*}, \mathrm{C}=\mathrm{N}\right), \\
\left(\pi-\pi^{*}, \text { aromatic }\right. \\
\text { ring })\end{array}$ & -- & - \\
\hline PCBT-Co & $425-650$ & $\begin{array}{c}4 \mathrm{~T} 1 \mathrm{~g}(\mathrm{~F}) \\
\rightarrow 4 \mathrm{~T} 1 \mathrm{~g}(\mathrm{P}) 4 \mathrm{~T} 1 \mathrm{~g} \\
(\mathrm{~F}) \rightarrow 4 \mathrm{~T} 2 \mathrm{~g}\end{array}$ & 5.95 & Octahedral \\
\hline PCBT-Ni & $450-750$ & $\begin{array}{c}{ }^{3} \mathrm{~A}_{2} \mathrm{~g} \rightarrow{ }^{3} \mathrm{~T}_{1} \mathrm{~g}(\mathrm{P}) \\
\mathrm{A}_{2} \mathrm{~g} \rightarrow{ }^{3} \mathrm{~T}_{2} \mathrm{~g}\end{array}$ & 3.9 & Octahedral \\
\hline PCBT-Cu & $425-750$ & $2 \mathrm{~B} 2 \rightarrow 2 \mathrm{E}$ & 1.89 & Tetrahedral \\
\hline PCBT-Zn & $560-720$ & $\mathrm{MLCT}$ & $\mathrm{Di}$ & Tetrahedral \\
\hline
\end{tabular}

\section{Measurement of Antioxidant activity:}

The percentage of the DPPH radical scavenging activity of CBT and its $\mathrm{Zn}^{\mathrm{II}}$ complex was calculated and the results was tabulated in table 5 and expressed in figure 9 .

Table-5: The percentage of the DPPH radical scavenging activity of CBT and its $\mathrm{Zn}$ (I ${ }^{\text {complex }}$

\begin{tabular}{rrr}
\hline Sample concentration $(\mu \mathrm{g} / \mathrm{ml})$ & DPPH scavenging \%(CBT) & DPPH scavenging \% $(\mathrm{CBT}-\mathrm{Zn})$ \\
\hline 1440 & 78.90 & 4.09 \\
\hline 720 & 70.77 & 3.47 \\
\hline 360 & 66.26 & 1.01 \\
\hline 180 & 35.03 & 0.62 \\
\hline 90 & 34.96 & 0.44 \\
\hline 45 & 34.81 & 0.34 \\
\hline 22.5 & 31.24 & 0.16 \\
\hline 0 & 0 & 0 \\
\hline
\end{tabular}

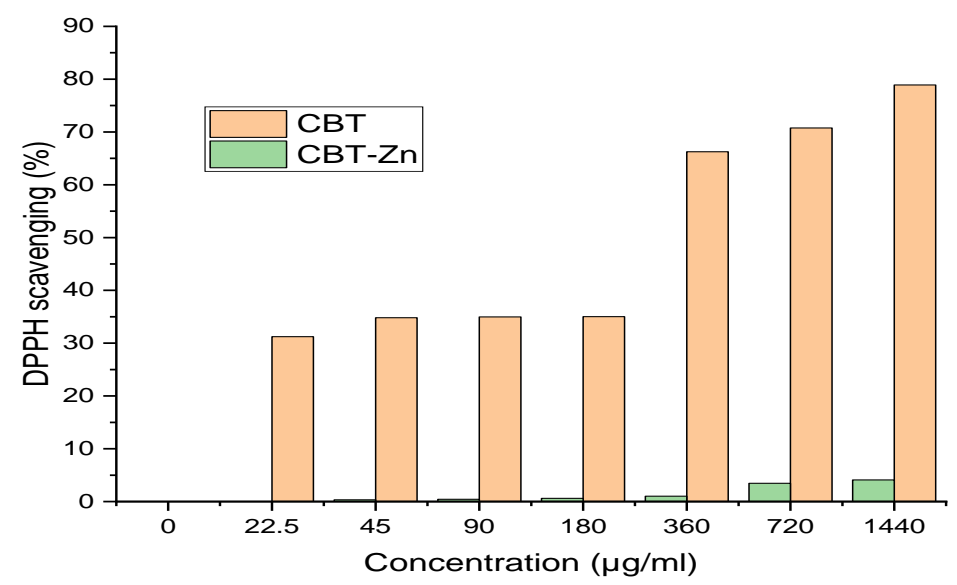

Figure-9: The DPPH radical scavenging activity of CBT and its $\mathrm{Zn}^{\mathrm{II}}$ complex

The percentage of the DPPH radical scavenging activity of PCBT and its $\mathrm{Co}^{\mathrm{II}}$ complex was calculated and the results was tabulated in table 6 and expressed in figure 10 . 
Table-6: The percentage of the DPPH radical scavenging activity of PCBT and its Co ${ }^{\text {II }}$ complex

\begin{tabular}{rrr}
\hline Sample concentration $(\mu \mathrm{g} / \mathrm{ml})$ & DPPH scavenging $\%($ PCBT $)$ & DPPH scavenging $\%($ PCBT-Co $)$ \\
\hline 1440 & 58.49 & 23.01 \\
\hline 720 & 55.39 & 18.63 \\
\hline 360 & 53.81 & 16.76 \\
\hline 180 & 53.73 & 7.83 \\
\hline 90 & 50.69 & 3.59 \\
\hline 45 & 45.39 & 1.97 \\
\hline 22.5 & 16.28 & 0.35 \\
\hline 0 & 0 & 0 \\
\hline
\end{tabular}

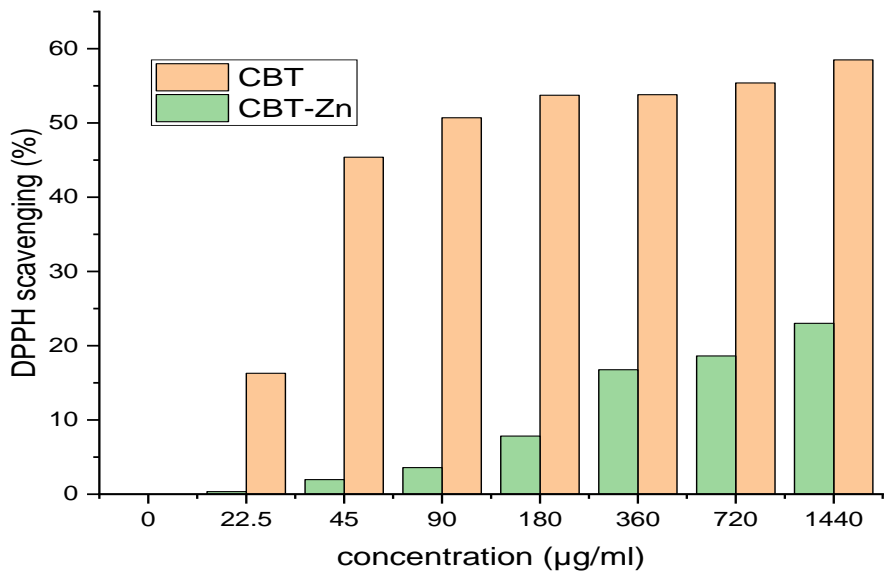

Figure-10: The DPPH radical scavenging activity of PCBT and its Co ${ }^{\mathrm{II}}$ complex

For comparison purpose, the effect of ascorbic acid as standard antioxidant was evaluated and produced (IC $\left.{ }_{50} \mathrm{ml}\right)$ under the same conditions table 7 and figure 11 .

Table-7: The percentage of the DPPH radical scavenging activity of Ascorbic acid

\begin{tabular}{|r|r|}
\hline Sample conc. $(\boldsymbol{\mu g})$ & DPPH scavenging \% \\
\hline 30 & $\mathbf{8 0 . 1 0}$ \\
\hline 25 & $\mathbf{7 6 . 9 9}$ \\
\hline 20 & $\mathbf{7 0 . 8 4}$ \\
\hline 15 & $\mathbf{5 4 . 7 0}$ \\
\hline 10 & 16.50 \\
\hline 5 & 11.76 \\
\hline 0 & 0 \\
\hline
\end{tabular}




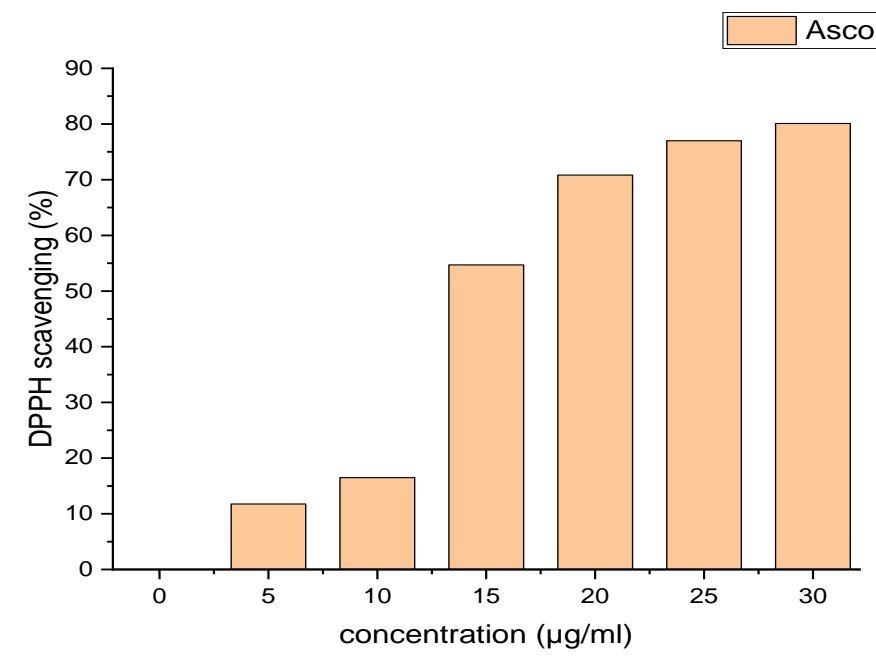

Figure-11: DPPH radical scavenging activity of Ascorbic acid

The reported results in terms of $\mathrm{IC}_{50}$ value was recorded in table 8

Table 8: $\mathrm{IC}_{50}$ values of Ascorbic acid and compounds under study

\begin{tabular}{|l|l|}
\hline Compound & $\mathbf{I C}_{\mathbf{5 0}}(\boldsymbol{\mu g} / \mathbf{m L})$ \\
\hline Ascorbic Acid & 14.4 \\
\hline CBT & 250 \\
\hline PCBT & 84 \\
\hline CBT-Zn & - \\
\hline PCBT-Co & - \\
\hline
\end{tabular}

\section{Corrosion Inhibition Measurements:}

Table 5 shows the calculated values of corrosion rate $\left(\mathrm{mg} \mathrm{cm} \mathrm{cm}^{-1}\right)$, inhibition efficiency $\left(\boldsymbol{\eta}_{\mathrm{w}}\right.$ $\%)$ and the degree of surface coverage $(\theta)$ for steel dissolution in $1.0 \mathrm{M} \mathrm{HCl}$ in the absence and presence of the surfactants under study. The values of corrosion rate were calculated from the following equation:

\section{$\mathbf{K}=\Delta \mathbf{W} / \mathbf{A t}$}

Where $\mathrm{k}$ is the corrosion rate $\left(\mathrm{mg} \mathrm{cm}^{-2} \mathrm{~h}^{-1}\right)$, $\Delta \mathrm{W}$ is the loss of weight after corrosion (mg), $\mathrm{A}$ is the total area of the coupon $\left(\mathrm{cm}^{2}\right)$, and $\mathrm{t}$ is the corrosion time (h). The degree of surface coverage $(\theta)$ and the inhibition efficiency, $\boldsymbol{\eta}_{\mathrm{w}} \%$, were calculated using the following equations[21]:

$$
\begin{gathered}
\theta=\frac{K_{0}-K}{K_{0}} \\
\eta \%=\frac{K_{0}-K}{K_{0}} \times 100
\end{gathered}
$$

Where $\mathrm{k}_{\mathrm{o}}$ and $\mathrm{k}$ are the values of the corrosion rate without and with addition of the inhibitor, respectively. From Table 9 we can find that:

For PCBT the inhibition efficiency percentage $\left(\boldsymbol{\eta}_{\mathrm{w}} \%\right)$ increases with increasing inhibitor concentration, which is due to the increase in the mass and charge transfer to the carbon steel surface leading to the adsorption of inhibitor molecules and reducing the metal dissolution. Also, more surface area $(\theta)$ is covered by increasing inhibitor concentration.

For the CBT it was found that the corrosion rate increases by increase the concentration and so the inhibition efficiency percentage and surface area decreases by increase the concentration. This can be explained by that the chloride in the ortho position have more electron withdrawal effect than the para position in PCBT this leads to decrease the charge transfer to the carbon steel surface which leads to increase corrosion. 
Table-9: Weight loss data for steel 1.0 M HCl without and with different concentrations of the ligands

\begin{tabular}{|c|c|c|c|c|}
\hline $\begin{array}{c}\text { Inhibitor } \\
\text { name }\end{array}$ & Conc.(M) & k (mg cm-2 h-1) & $\Theta$ & $\eta w \%$ \\
\hline Blank & $0 \times 10^{-4}$ & 1.5916 & ----- & ----- \\
\hline \multirow[t]{5}{*}{ CBT } & $0.5 \times 10^{-4}$ & 1.5916 & 0 & 0 \\
\hline & $0.75 \times 10^{-4}$ & 1.75 & -0.15 & -15 \\
\hline & $2.5 \times 10^{-4}$ & 1.84 & -0.248 & -24.8 \\
\hline & $5 \times 10^{-4}$ & 2.083 & -0.3225 & -32.25 \\
\hline & $7.5 \times 10^{-4}$ & 2.173 & -0.4914 & -49.14 \\
\hline \multirow[t]{5}{*}{ PCBT } & $0.5 \times 10^{-4}$ & 1.563 & 0.0177 & 1.77 \\
\hline & $0.75 \times 10^{-4}$ & 1.24 & 0.2199 & 21.99 \\
\hline & $2.5 \times 10^{-4}$ & 0.74 & 0.535 & 53.5 \\
\hline & $5 \times 10^{-4}$ & 0.705 & 0.557 & 55.7 \\
\hline & $10 \times 10^{-4}$ & 0.5 & 0.6858 & 68.58 \\
\hline
\end{tabular}

\section{Adsorption Isotherm}

According to corrosion studies it is important to know the relationship between the inhibitor molecules and the surface of the metal which obtained by the adsorption of these molecules on the metal surface by two different types of adsorption. Generally, adsorption of an inhibitor maybe classified as a physical adsorption and chemisorption. The main factors affecting the adsorption type are the electronic structure of the metal, the type of electrolyte and the chemical structure of the inhibitor. Furthermore, adsorption process take place when the water molecules $\left(\mathrm{H}_{2} \mathrm{O}(\mathrm{ads})\right.$ which were previously adsorbed on the metal surface are replaced by the inhibitor molecules $\left(\mathrm{Inh}_{(\mathrm{sol})}\right)$ present in the aqueous solution as follows:

$$
\mathrm{Org}_{(\mathrm{sol})}+\mathrm{x} \mathrm{H}_{2} \mathrm{O}_{(\mathrm{ads})} \rightarrow \mathrm{Org}_{(\mathrm{ads})}+\mathrm{x} \mathrm{H}_{2} \mathrm{O}_{(\mathrm{sol})}
$$

Where $\mathrm{x}$ is the size ratio representing the number of water molecules replaced by one organic molecule. Different adsorption isotherm equations such as Freundlich, Langmuir, Frumkin, Flory-Huggins, Frumkin and Temkin can be applied to the resulted data resulted, but it was found that the data are more likely to fit with the Langmuir isotherm especially when the correlation coefficients $\left(\mathrm{R}^{2}\right)$ for $\mathrm{CBT}$ and PCBT are 0.8119 and 0.0535 respectively figure 12 and 13 . The Langmuir relation is as follow:

Langmuir Isotherm $=\mathrm{C}_{\mathrm{inh}} / \theta=1 / \mathrm{k}_{\mathrm{ads}}+\mathrm{C}_{\mathrm{inh}}$ Where $\mathrm{C}_{\mathrm{inh}}$ is the inhibitor concentration; $\mathrm{K}_{\mathrm{ads}}$ is the equilibrium constant of the isotherm process and $\theta$ is the degree of surface coverage. By plotting $\mathrm{C}_{\mathrm{inh}} / \theta$ versus $\mathrm{C}$, it was found that the slope of Langmuir adsorption isotherm for the three synthesized inhibitor PCBT at $30{ }^{\circ} \mathrm{C}$ was almost close to unity except a slight deviation took place which may be referred to the interaction between the adsorbed inhibitor molecules with each other[22, 23].Values of the equilibrium constant $\left(\mathrm{K}_{\mathrm{ads}}\right)$ for inhibitor PCBT were $3.376 \times 10^{3}$, $45.88 \times 10^{3}$ and $0.726 \times 10^{3}$ respectively, these values indicates how strong the adsorption force between the synthesized inhibitors and the surface of the metal. It is also known that the equilibrium constant $\left(\mathrm{K}_{\mathrm{ads}}\right)$ is related to the Gibbs free energy according to the equation [24]:

$$
\Delta G_{a d s}^{\circ}=-R T \ln \left(55.5 K_{a d s}\right)
$$

Where (55.5) is the molar concentration of water in solution expressed in mole/l, $R(8.314)$ is the universal gas constant and $T$ is the absolute temperature. Generally, when $\boldsymbol{\Delta} \boldsymbol{G}^{\circ}$ ads values are equal to -20 or higher it may be considered as (Physical adsorption), while values of -40 or lower are of the type (chemisorption)[25]. Calculated values of the Gibbs free energy for inhibitors MBT and PCBT were 30.58834 and - $26.7168 \mathrm{KJ} \mathrm{mol}^{-1}$ as tabulated in Table 10. So it is obvious that this values indicating that the adsorption processes were of chemically adsorption type on the surface of the carbon steel that also indicating an electron transfer process took place to form a coordination bond between the inhibitor molecules and the d-orbital of the iron molecules[26, 27].

Table-10: Thermodynamic parameters using Langmuir adsorption isotherm on steel surface in $1.0 \mathrm{M} \mathrm{HCl} \mathrm{containing}$ different concentrations of the ligands MBT and PCBT

\begin{tabular}{|l|l|l|l|l|l|}
\hline Inhibitor & $\begin{array}{l}\text { Temp. } \\
\left({ }^{\circ} \mathbf{k}\right)\end{array}$ & $\begin{array}{l}\mathbf{K}_{\text {ads }} \\
(\mathbf{K J} / \mathbf{m o l})\end{array}$ & $\begin{array}{l}\Delta \mathbf{G}_{\text {ads }} \\
(\mathbf{K J} / \mathbf{m o l})\end{array}$ & $\begin{array}{l}\Delta \mathbf{S}_{\text {ads }} \\
\left(\mathbf{J} / \mathbf{m o l} .{ }^{\mathbf{o}} \mathbf{k}\right)\end{array}$ & $\begin{array}{l}\Delta \mathbf{H}_{\text {ads }} \\
(\mathbf{K J} / \mathbf{m o l})\end{array}$ \\
\hline MBT & 303 & 3376.074458 & -30.58834 & 0.304748049 & 61.75 \\
\hline PCBT & 303 & 726.2650946 & -26.7168 & 0.500414166 & 124.91 \\
\hline
\end{tabular}




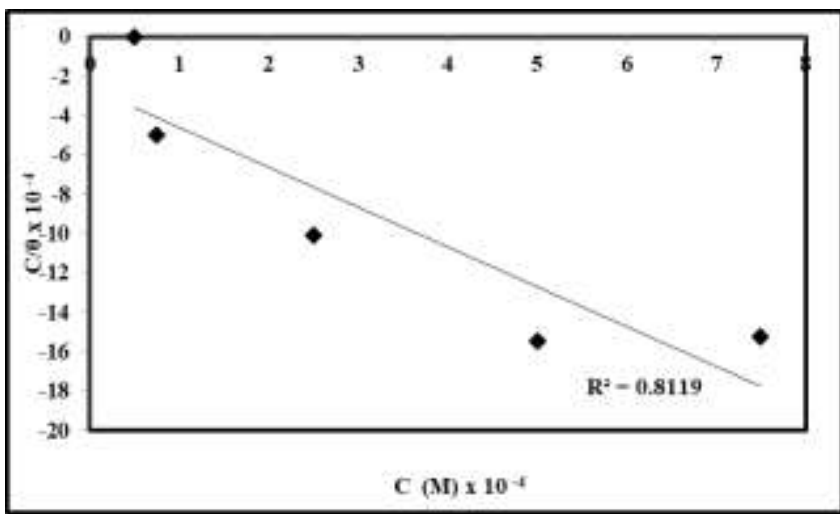

Figure-12: Langmuir isotherm adsorption model on the carbon steel surface of Schiff base inhibitor CBT in 1.0 M $\mathrm{HCl}$ at $30^{\circ} \mathrm{C}$

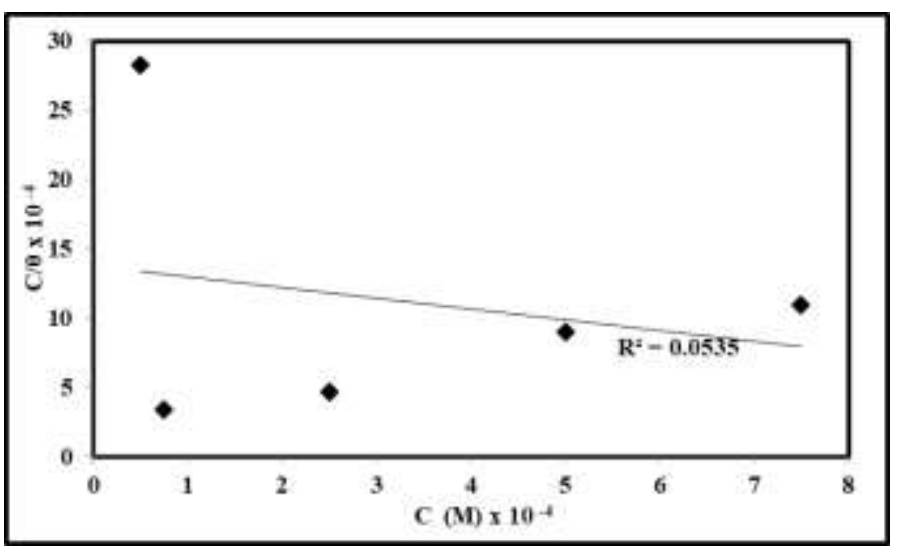

Figure-13: Langmuir isotherm adsorption model on the carbon steel surface of Schiff base inhibitor PCBT in 1.0 $\mathrm{MHCl}$ at $30{ }^{\circ} \mathrm{C}$

Enthalpy $\left(\Delta \mathbf{H}_{\mathrm{ads}}\right)$ and Entropy $\left(\Delta \mathbf{S}_{\mathrm{ads}}\right)$ of Adsorption:

Enthalpy and Entropy of adsorption can be calculated as follows:

$$
\begin{gathered}
\ln K_{a d s}=\left(\frac{\Delta H_{a d s}}{R T}\right)+\text { const } \\
\Delta G=\Delta H_{a d s}-T \Delta S_{a d s}
\end{gathered}
$$

Where $\Delta H_{a d s}$ and $K_{a d s}$ are the adsorption heat and adsorptive equilibrium constant, respectively. Plotting $\ln K_{a d s}$ against $1 / T$ gives straight link which slope is equal to $\Delta H_{a d s} / \mathrm{R}$. Negative values of $\Delta H_{a d s}$ are shown in Table 10 indicating that the adsorption of inhibitors is exothermic in nature. Also, the negative values of $\Delta H_{a d s}$ show that the adsorption is exothermal with an ordered phenomenon ascribed by the negative values of $\Delta S_{a d s}$. This order may more probably be explained by the possibility of formation of iron complex on the metal surface [28, 29].

\section{CONCLUSION}

DMSO solution of the compounds under study showed good antioxidant potential by DPPH radical scavenging method when compared to standard ascorbic acid and $\mathrm{IC}_{50}$ value found to be $14.4 \mu \mathrm{g} / \mathrm{ml}$ for ascorbic acid, $250 \mu \mathrm{g} / \mathrm{ml}$ for CBT and $844 \mu \mathrm{g} / \mathrm{ml}$ for PCBT where the complexes show low activity. And then by study the anticorrosion activity of ligands CBT and PCBT showed that: PCBT has good inhibition efficiency as inhibitor for carbon steel dissolution in $1.0 \mathrm{M} \mathrm{HCl}$ solution, but CBT cannot be used as corrosion inhibitor.

So, it can be said that some of thiourea derivatives can be useful for man health as antioxidants and economy as anticorrosive agents.

\section{REFERENCES}

1. Kumar, A., B.G. Varadaraj, and R.K.J.B.o.F.o.P. Singla, Cairo University, Synthesis and evaluation of antioxidant activity of novel 3, 5-disubstituted2-pyrazolines. 2013. 51(2): p. 167-173.

2. Taha, M., et al., Synthesis, evaluation of antioxidant activity and crystal structure of 2, 4dimethylbenzoylhydrazones. 2013. 18(9): p. 10912-10929.

3. Júnior, J.M.F., et al., Evaluation of antioxidant activity and inhibition of corrosion by Brazilian plant extracts and constituents. 2016. 11: p. 38623875.

4. Benali, O., et al., Green corrosion inhibitor: inhibitive action of tannin extract of Chamaerops humilis plant for the corrosion of mild steel in 0.5 M H2SO4. 2013. 4(1): p. 127-138.

5. Karakuş, S. and S.J.I.F. Rollas, Synthesis and antituberculosis activity of new N-phenyl-N'-[4- 
(5-alkyl/arylamino-1, 3, 4-thiadiazole-2-yl) phenyl] thioureas. 2002. 57(7): p. 577-581.

6. Solomon, V., et al., 4-Aminoquinoline derived antimalarials: synthesis, antiplasmodial activity and heme polymerization inhibition studies. 2010. 45(11): p. 4990-4996.

7. Holt, S.L. and R.L.J.J.o.t.A.C.S. Carlin, Some Transition Metal Complexes of Substituted Thioureas. II. Nickel (II). 1964. 86(15): p. 30173024.

8. Puglisi, C., R.J.J.o.I. Levitus, and N. Chemistry, Some substituted thiourea complexes of nickel (II) thiocyanate. 1967. 29(4): p. 1069-1077.

9. Leaves, L.J.A.J.o.E., Antioxidant activity by DPPH radical scavenging method of ageratum conyzoides. 2014. 1(4): p. 244-249.

10. Byahatti, V.V., K.V. Pai, and M.G.J.A.s.o.1. D'Souza, Effect of phenolic compounds from Bergenia ciliata (Haw.) Sternb. leaves on experimental kidney stones. 2010. 30(1): p. 14.

11. Harborne, A., Phytochemical methods a guide to modern techniques of plant analysis. 1998: springer science $\&$ business media.

12. Srisailam, K., K. Vijayabhaskar, and N. Gowrishankar, ANTIOXIDANT ACTIVITY BY DPPH RADICAL SCAVENGING METHOD OF METHANOLIC EXTRACT OF N-BUTANOL FRACTRION OF TRIBULUS TERRESTRIS LINN.(FAMILY ZYGOPHYLLACEAE).

13. Wagner, H. and S.J.P.D.A.A.T.L.C.A. Bladt, Alkaloid drugs. 1996: p. 3-51.

14. Handa, S., D. Rakesh, and K.J.I.U.A. Vasisht, Compendium of medicinal and aromatic plants Asia'. 2006. 2: p. 305.

15. Varier, V.J.P., Madras, India, Indian medicinal plants: a compendium of 500 species Orient Longman. 1996. 134.

16. Ahmad, M., et al., Evaluation of insecticidal and antioxidant activity of selected medicinal plants. 2013. 2: p. 153-158.

17. Patel Rajesh, M., J.J.J.o.A.P.E. Patel Natvar, and Research, In vitro antioxidant activity of coumarin compounds by DPPH, Super oxide and nitric oxide free radical scavenging methods. 2011. 1: p. 52-68.

18. Achola, K. and R.J.P.b. Munenge, Bronchodilating and uterine activities of Ageratum conyzoides extract. 1998. 36(2): p. 93-96.

19. Ali M H, Zaghloul I , Khalid M W. Synthesis, Characterization, Biological and Antitumor Activity of $\mathrm{Co}(\mathrm{II}), \mathrm{Ni}$ (II) , $\mathrm{Cu}(\mathrm{II})$ and $\mathrm{Zn}$ (II) Complexes of N-(2-Chlorophenyl)-N'-Benzoyl Thiourea. Organic \& Medicinal Chem IJ. 2020; 9(4): $\quad 555767 . \quad$ DOI: 10.19080/OMCIJ.2020.09.555767.
20. Ali MH, Zaghloul IE, and Khalid MW. "Microwave, Synthesis, Characterization, Biological Activity of N- (p-Chlorophenyl)-N'Benzoyl Thiourea and its Complexes". Chem Sci J 11 (2020) doi: 10.37421/csj.2020.11.208.

21. Bedair. M. A, Soliman. S. A, Metwally. M. S. Synthesis and characterization of some nonionic surfactants as corrosion inhibitors for steel in $1.0 \mathrm{M}$ $\mathrm{HCl}$ (Experimental and computational study). Journal of Industrial and Engineering Chemistry, 41, pp. 10-22, 2016

22. Bedair. M. A, El-Sabbah. M. M. B, Fouda. A. S, Elaryian. H. M. Synthesis, electrochemical and quantum chemical studies of some prepared surfactants based on azodye and Schiff base as corrosion inhibitors for steel in acid medium. Corrosion Science, 128, pp. 54-72, 2017.

23. Tao. Z, Zhang. S, Li. W, Hou. B. Corrosion inhibition of mild steel in acidic solution by some oxo-triazole derivatives. Corrosion Science, 51(11), pp. 2588-2595, 2009.

24. John. S. A. M, Ali. K. M, Joseph. A. Electrochemical, surface analytical and quantum chemical studies on Schiff bases of 4-amino-4H-1, 2, 4-triazole-3,5-dimethanol (ATD) in corrosion protection of aluminium in $1 \mathrm{~N} \mathrm{HNO3.} \mathrm{Bulletin} \mathrm{of}$ Materials Science, 34(6), pp. 1245-1256, 2011.

25. Sobhi. M, El-sayed. R, Abdallah. M. The Effect of Non Ionic Surfactants Containing Triazole, Thiadiazole and Oxadiazole as Inhibitors of the Corrosion of Carbon Steel in $1 \mathrm{M}$ Hydrochloric Acid. Journal of Surfactants and Detergents, 16(6), pp. 937-946, 2013.

26. Abd El-Lateef. H. M. Experimental and computational investigation on the corrosion inhibition characteristics of mild steel by some novel synthesized imines in hydrochloric acid solutions. Corrosion Science, 92, pp. 104-117, 2015.

27. Abd El-Lateef. H. M, Abo-Riya. M. A, Tantawy. A. H. Empirical and quantum chemical studies on the corrosion inhibition performance of some novel synthesized cationic gemini surfactants on carbon steel pipelines in acid pickling processes. Corrosion Science, 108, pp. 94-110, 2016.

28. Haque. J, Ansari. K. R, Srivastav. V, Quraishi. M. A, Obot. I. B. Pyrimidine derivatives as novel acidizing corrosion inhibitors for N80 steel useful for petroleum industry: A combined experimental and theoretical approach. Journal of Industrial and Engineering Chemistry, 49, pp. 176-188, 2017.

29. Herrag. L, Chetouani. A, Elkadiri. S, Hammouti. B, Aouniti. A. Pyrazole Derivatives as Corrosion Inhibitors for Steel in Hydrochloric Acid. Portugaliae Electrochimica Acta, 26, pp. 211-220, 2008. 